\title{
Comparative evaluation of the anti-plaque efficacy of green tea extract mouthrinse and white tea extract mouthrinse with chlorhexidine gluconate mouthrinse-A clinical and microbiological study
}

\author{
Ayushi Nagar ${ }^{1, *}$, Anubhuti Tyagi ${ }^{2}$, Swyeta Jain Gupta $^{3}$, Akanksha Banga ${ }^{4}$, Nikhil Sharma ${ }^{5}$, Amit Gupta $^{6}$ \\ ${ }^{1,2}$ BDS Student, ${ }^{3,4}$ Senior Lecturer, ${ }^{5} \mathrm{HOD},{ }^{6}$ Reader, ${ }^{1,2,3,5}$ Dept. of Periodontology and Oral Implantology, ${ }^{4}$ Dept. of Oral and \\ Maxillofacial Pathology, ${ }^{1-5}$ I.T.S Centre for Dental Studies and Research, Muradnagar, Ghaziabad, Uttar Pradesh, ${ }^{6}$ I.T.S Dental \\ College, Hospital and Research Centre, Greater Noida, Uttar Pradesh, India
}

*Corresponding Author:

Email: ayushinagar.ayu@gmail.com

\begin{abstract}
Introduction: Numerous studies have been conducted based on the natural mouthwashes, with fewer side effects, as an alternative to chemical ones. The aim of this study is to compare clinically and microbiologically the anti plaque efficacy of mouthwash containing extract of green tea, white tea extract with chlorhexidinegluconate mouthwash.

Materials and Methods: This clinical study was performed in the department of Periodontology and Oral Implantology, I.T.S Dental College, Muradnagar, Ghaziabad, India. All the patients were educated about the study and then a written informed consent was acquired before enrolment in the study. The study was conducted for a period of 10 days.

A total of 30 Dental students were selected as patients of age group of 19-23 years(from $1^{\text {st }}$ to $2^{\text {nd }}$ year) according to assigned inclusion criteria, oral prophylaxis was performed \& the subjects were randomly allocated equally to one of the three treatment groups (10 each) Group A - Green Tea Extract, Group B - White Tea Extract, Group C- Chlorhexidinegulconate. The subjects were assessed both preoperatively and postoperatively clinically by recording the plaque and gingival indices and microbiologically by counting the number of colonies forming units $/ \mathrm{mL}(\mathrm{CFU} / \mathrm{mL})$.

Results: Green Tea showed statistically significant difference in clinical parameters and in CFUs/ml compared to White Tea.

Conclusion: The results of the current study indicated that White Tea and Green Tea mouth rinse were found to be a potent antiplaque agent although less efficacious than chlorhexidine mouth rinse. Green tea catechin mouthwash was comparably efficacious to chlorhexidinegluconate as an antiplaque agent when used for 10 days.
\end{abstract}

Keywords: Green tea, White tea, Chlorhexidinegluconate mouth rinse, Antiplaque.

\section{Introduction}

Oral disease or disease pertaining to mouth are often associated with gum diseases (gingivitis), and periodontitis which is a condition in which supporting structures and bone are destroyed and subsequently teeth would corrupt and exfoliate. One of the leading prevalent cause of periodontal disease is gingivitis mainly induced by plaque affecting $90 \%$ of the population, regardless of age, gender, or ethinicity. ${ }^{1}$ In more developed countries, the prevalence and the severity of the gingivitis varies in accordance to the age range. The gingivitis' prevalence among juvenile is reported to be $61.5 \%$ in USA, $85 \%$ in Australia and 95\% in India. Dental plaque (bacterial biofilm) on the surface of teeth is accounted as the main cause of gingivitis. However, other factors include systemic disease, hormonal changes, gender, age, economic conditions which may also affect the response of gingival tissue to prevailing dental plaque. ${ }^{2}$ Mechanical cleaning methods have been proven to be the quite effective way for the plaque control and in turn gingivitis. However, since tooth brushing is not adequately and efficiently practiced by majority population, the additional incorporation of chemical agents, such as chlorhexidine and triclosan, ${ }^{3}$ have emerged as an effective adjunct. A wide array of synthetic mouthwashes are available commercially; but chlorhexidine, which has been approved by ADA and FDA is regarded as the most effective antibacterial mouthwash. Green tea extract can be used as another herbal mouthwash, however its processing is under investigation. During recent years, the health benefits of green tea have been researched thoroughly, and in recent studies correlation between green tea and reduction of periodontal diseases has been established. Tea is an ancient beverage procured from the leaves Camellia Sinensis, a tropical green shrub or small tree. Catechins, the key constituent to tea's health benefits, is credited to its ability to act as anitioxidant. When drawing a comparison from black tea, green tea has higher concentration of polyphenol. Catechin supresses the periodontal inflammation, thereby ensuring better dental and gingival health. ${ }^{4}$ Catechin, an antioxidant compound may also exhibit anti-inflammatory effect. Tea polyphenol prevents the plaque formation over the teeth's enamel surface, thus in turn minimising the risk of dental caries as well. Furthermore, green tea has been found to combat bacterial growth, the fore bearer step of malodour (halitosis). Some varities also contain fluorides which helps strengthening the teeth. Along with these benefits, it also has ability to reduce gum diseases.

White tea originates from the plant Cameliasinensis. White tea has a light taste and color. The origin of white tea is mostly from Fujian Province 
of china and is least processed form of tea with least amount of caffeine as compared to black and green tea the ingredients of white tea are alanine, and amino acids. The most important ingredients in white tea are rich in polyphenols, which is natural antioxidant. It has many health benefits, as it can combat bacteria, fungi, and viruses in the body more successfully than other variant.

\section{Materials and Methods}

The current clinical trial was double blinded, randomized parallel, longitudinal study. Thirty periodontally healthy subjects between the age group of 19-23 years were enrolled in a 10 day rinsing study. Mouthwashes were labelled as A-Green Tea, B-White Tea and C- $0.2 \%$ Chlorhexidine gluconate by the examiner.

Green Tea and White Tea mouthwashes were prepared by boiling $1 \mathrm{mg}$ of green and white tea extract in $10 \mathrm{ml}$ of distilled water for 5 minutes. No preservatives or flavouring agents were added.

Subjects with good systemic health with atleast 24 scorable teeth (not including third molar or crowned teeth) were taken in the study. Subjects having high consumption of polyphenolic diet (including green tea or soya diet), wore appliances, or prostheses (removable or fixed), those were on prescribed antibiotics and other medication for the previous 3 months or the ones who had undergone treatment for periodontal problems were excluded from the study.

This study was approved by the ethical committee of the same ITS Dental college, Muradnagar, Ghaziabad.

The subjects were randomly assigned into three equal groups A, B and C (10 subjects in each group)

At baseline, thorough oral prophylaxis was performed for all the subjects by the investigator. Plaque sample were collected at baseline and 10 days. Subjects were told not to use interdental aids or chewing gums for the next 10 days. Subjects were asked to use one of the assigned mouthwash two times a day at a particular specified time during the day for $1 \mathrm{~min}$ with $10 \mathrm{ml}$ of randomly allocated rinse. At each rinsing, $10 \mathrm{ml}$ of the solution was made to swish around the mouth for about $60 \mathrm{sec}$ and then expectorated.

At baseline and $10^{\text {th }}$ day; plaque index (PI) and gingival index (GI) were recorded and subjects were allowed to recommense their routine oral hygiene regimens post $10^{\text {th }}$ day.

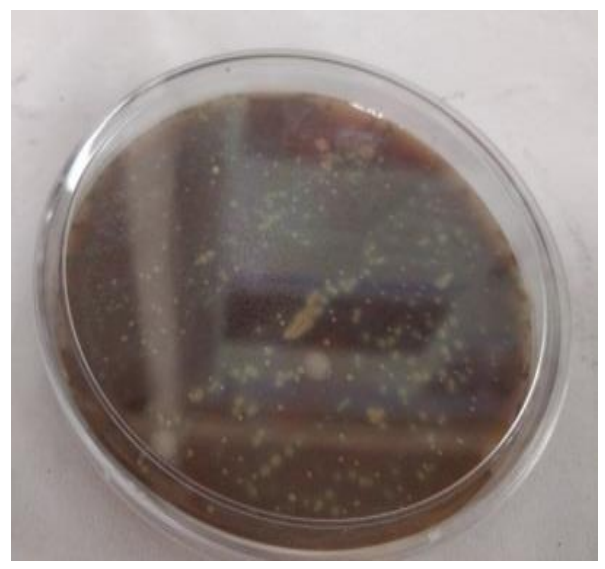

Fig. 1: Colony forming units

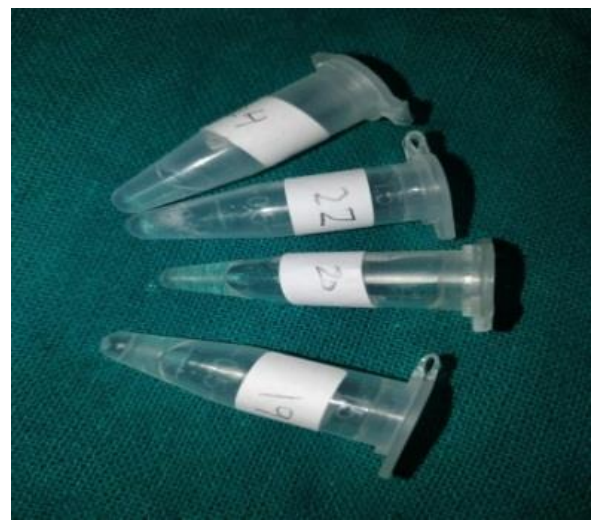

Fig. 2: Samples collected

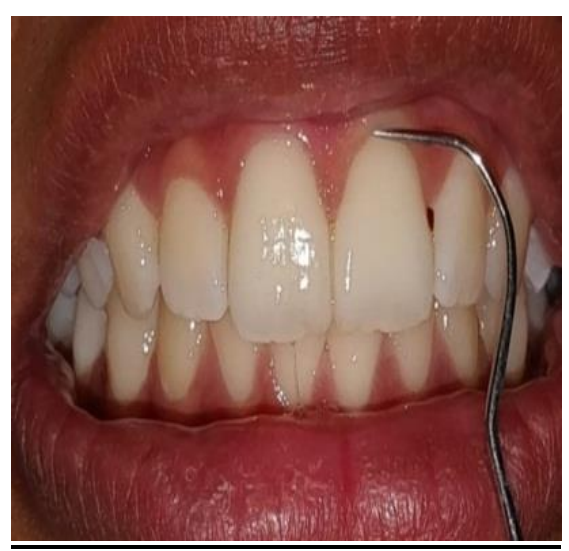

Fig. 3: Plaque index

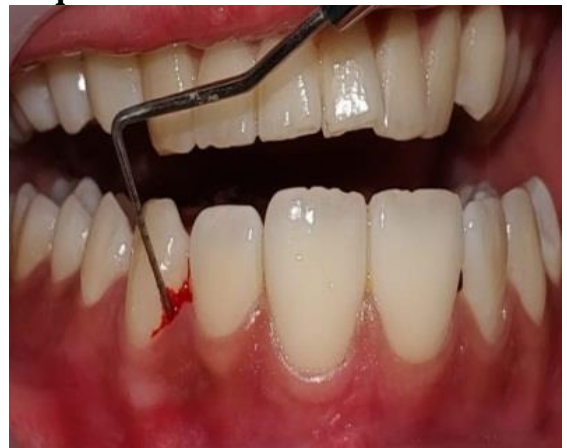

Fig. 4: Gingival index 


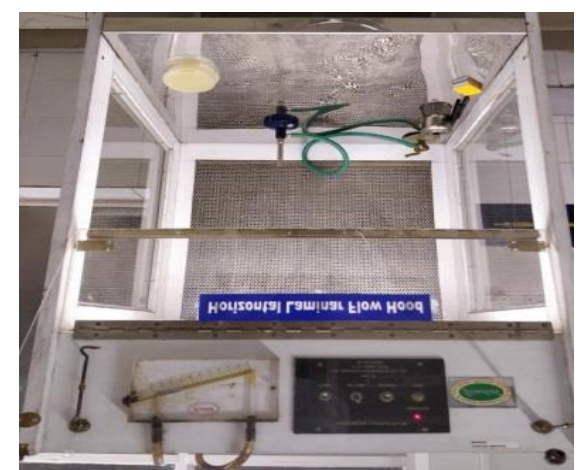

Fig. 5: Incubation chamber fig 6 colony counter

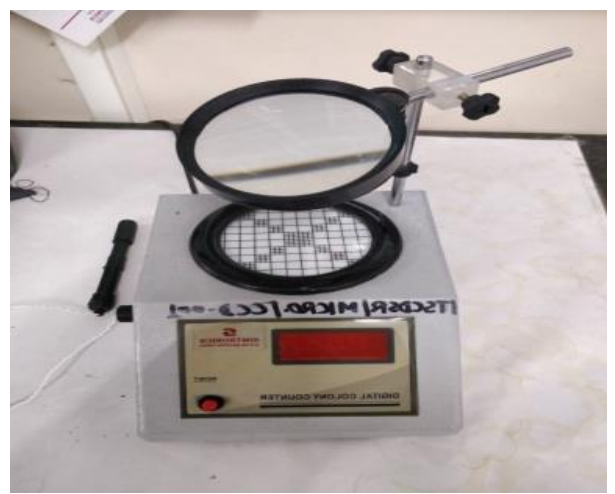

Fig. 6: Colony counter

\section{Results}

Thirty subjects, 9 males and 21 females comprised of the present study. The results are presented in table 1 and 2. Chlorhexidene showed statistically better result in relation to Plaque Index, Gingival Index and Colony Forming Units as compared to Green Tea and White Tea extract mouthwash. The results demonstrated that the values of PI evaluated were comparable for both Green Tea and White Tea but in respect to GI and CFUs Green Tea extract mouthwash showed statistically significant reduction in scores as compared to White Tea extract mothwash (Table 1). Difference between the individual mouthwashes were determined through the multiple comparison in Table 2 and further graph was plotted showing the mean pre and post difference between the gingival index, plaque index and CFU for individual mouthwashes. (Fig. 1,2)

There was no burning sensation or taste alteration reported by any of the participants at the end of the study period. In addition, there was no evidence of gingival epithelial desquamation on intraoral examination in any of the subjects.

\section{Discussion}

The present study compared and evaluated the anti plaque effects of the newly formulated white tea mouthwash, green tea mouthwash, and chlorhexidine gluconate mouthwash.

Green tea is a variety of tea derived from Camellasinesis, a topical evergreen shrub, is a potent antioxidant and has anti-inflammatory properties. Most of the biological properties of green tea have been attributed to the catechin fraction, which possesses certain therapeutic and biological properties, Catechin such as Epigallocatechin-3-gallate (EGCG) is intercalated into phospholipid bilayers and it is thought to effect both virulence and antibiotic resistance. It exerts inhibitory effect on S.mutans growth, which are primarily responsible for caries and gingivitis. ${ }^{4}$ Catechins have pronounced role to play on $\mathrm{pH}$ value of saliva and dental plaque and keep it preserved to normal range (7.2-7.4) which is not a favourable condition for growth of S.Mutans. The mechanism of action of tea's health benefit comes from prevention of oxidation. The concentration of polyphenol is quite high (the major antioxidant in green tea leaves). ${ }^{5}$ Catechins have been found to have antiplaque and antibacterial properties and prevention in gingival enlargement. Hirasawa et al demonstrated bactericidal potential of green tea catechins at $1 \mathrm{mg} / 1 \mathrm{ml}$ against Prevotella and P. gingivalis species and observed a significant reduction in cytokine profile markers of gingivitis post using it as a slow-release buccal delivery system applied over a period of 8 weeks. ${ }^{6}$ Green tea catechin also has an interdictory effect on collegenase activity, thus limiting tissue destruction. It has found to minimise matrix metalloproteinase- 9 expression in osteoblasts and also inhibits the formation of osteoclasts. Thus, EGCG may prevent alveolar bone resorption that occur in periodontal disease. ${ }^{7}$

White tea consists of mainly fluoride, tannins and flavinoids which is effective in caries reduction and inhibitory effect on the growth of bacteria. White tea mouthrinse was found to be a potent antiplaque agent, though less efficacious than chlorhexidine and green tea mouthrinse. Probably, it can serve as a long term herbal antiplaque agent in maintenance phase or as an alternative for the patients looking for herbal products mouthrinse, or for the patients who complaint of sideeffects due to chlorhexidine mouthrinse.

Chlorhexidine gluconate is gold standard against which antiplaque and antigingivitis agents' potential are measured. It comes under second generation Bisbiguanides.

This study hence signifies the efficacy of a green tea catechin mouth wash, white tea extract mouthwash and chlorhexidine gluconate mouthrinseas an antiplaque agent compared over a 10 day period .One shortcoming of this study is the small sample size. However, sufficient sample size was found when power calculations were performed prior to the beginning of the study. More extensive studies using a longer duration span, larger sample sample size and a crossover model can be performed for further research.

\section{Conclusion}

The results of thecurrent study indicated that White Tea And Green Tea mouth rinse was found to be a 
potent anti plaque agent although less efficacious than chlorhexidine mouth rinse .Green tea catechin mouthwash was comparably efficacious to chlorhexidine gluconate as an antiplaque agent when used for 10 days. Furthermore, green tea catechin mouthwash having more palatable taste and no known significant side-effects can be used on a day today basis as an alternative for chlorhexidine gluconate as an antiplaque agent. It should be further explored and evaluated as a long term antiplaque rinse with prophylactic benefits.

Green Tea and white tea can serve as a good alternative for patients who prefer herbal products which have practically no side effects.

Table 1: Comparison of various clinical parameters and CFU at baseline and 10 days

\begin{tabular}{|c|c|c|c|c|c|c|c|}
\hline \multirow[t]{2}{*}{$\begin{array}{l}\text { Clinical } \\
\text { Parameter }\end{array}$} & \multirow[t]{2}{*}{ Group } & \multirow[t]{2}{*}{$\mathbf{N}$} & \multirow[t]{2}{*}{ Mean } & \multirow[t]{2}{*}{$\begin{array}{c}\text { Std. } \\
\text { Deviation }\end{array}$} & \multirow[t]{2}{*}{ Std. Error } & \multicolumn{2}{|c|}{$\begin{array}{l}\text { 95\% Confidence } \\
\text { Interval for Mean }\end{array}$} \\
\hline & & & & & & $\begin{array}{l}\text { Lower } \\
\text { Bound }\end{array}$ & $\begin{array}{l}\text { Upper } \\
\text { Bound }\end{array}$ \\
\hline \multirow[t]{4}{*}{ PI PRE } & Chlorhexidine & 10 & 1.58 & .365 & .115 & 1.32 & 1.84 \\
\hline & White tea & 10 & 1.51 & .448 & .142 & 1.19 & 1.83 \\
\hline & Green tea & 10 & 1.55 & .354 & .112 & 1.29 & 1.80 \\
\hline & Total & 30 & 1.55 & .379 & .069 & 1.40 & 1.69 \\
\hline \multirow[t]{4}{*}{ PI POST } & Chlorhexidine & 10 & .6380 & .17574 & .05557 & .5123 & .7637 \\
\hline & White tea & 10 & .7810 & .31988 & .10115 & .5522 & 1.0098 \\
\hline & Green tea & 10 & .9710 & .32760 & .10360 & .7366 & 1.2054 \\
\hline & Total & 30 & .7967 & .30642 & .05594 & .6822 & .9111 \\
\hline \multirow[t]{4}{*}{ GI PRE } & Chlorhexidine & 10 & 1.5970 & .17525 & .05542 & 1.4716 & 1.7224 \\
\hline & White tea & 10 & 1.3560 & .17946 & .05675 & 1.2276 & 1.4844 \\
\hline & Green tea & 10 & 1.4490 & .25623 & .08103 & 1.2657 & 1.6323 \\
\hline & Total & 30 & 1.4673 & .22381 & .04086 & 1.3838 & 1.5509 \\
\hline \multirow[t]{4}{*}{ GI POST } & Chlorhexidine & 10 & .5630 & .13889 & .04392 & .4636 & .6624 \\
\hline & White tea & 10 & .7590 & .13755 & .04350 & .6606 & .8574 \\
\hline & Green tea & 10 & .6590 & .15249 & .04822 & .5499 & .7681 \\
\hline & Total & 30 & .6603 & .16031 & .02927 & .6005 & .7202 \\
\hline \multirow[t]{4}{*}{ CFU PRE } & Chlorhexidine & 10 & 115.70 & 16.255 & 5.140 & 104.07 & 127.33 \\
\hline & White tea & 10 & 113.00 & 18.172 & 5.746 & 100.00 & 126.00 \\
\hline & Green tea & 10 & 110.80 & 11.153 & 3.527 & 102.82 & 118.78 \\
\hline & Total & 30 & 113.17 & 15.075 & 2.752 & 107.54 & 118.80 \\
\hline \multirow[t]{4}{*}{ CFU POST } & Chlorhexidine & 10 & 69.60 & 11.946 & 3.778 & 61.05 & 78.15 \\
\hline & White tea & 10 & 90.80 & 10.768 & 3.405 & 83.10 & 98.50 \\
\hline & Green tea & 10 & 72.60 & 9.594 & 3.034 & 65.74 & 79.46 \\
\hline & Total & 30 & 77.67 & 14.128 & 2.579 & 72.39 & 82.94 \\
\hline
\end{tabular}

Table 2: Multiple comparisons between various mouthwashes

\begin{tabular}{|c|c|c|c|c|c|c|c|}
\hline \multirow[t]{2}{*}{$\begin{array}{l}\text { Dependent } \\
\text { Variable }\end{array}$} & \multirow[t]{2}{*}{ Group } & \multirow[t]{2}{*}{ Group } & \multirow[t]{2}{*}{$\begin{array}{c}\text { Mean } \\
\text { Difference }\end{array}$} & \multirow[t]{2}{*}{$\begin{array}{l}\text { Std. } \\
\text { Error }\end{array}$} & \multirow[t]{2}{*}{ Sig. } & \multicolumn{2}{|c|}{$\begin{array}{c}\text { 95\% Confidence } \\
\text { Interval }\end{array}$} \\
\hline & & & & & & $\begin{array}{l}\text { Lower } \\
\text { Bound }\end{array}$ & $\begin{array}{l}\text { Upper } \\
\text { Bound } \\
\end{array}$ \\
\hline \multirow[t]{6}{*}{ PI PRE } & \multirow[t]{2}{*}{ Chlorhexidine } & White tea & .071 & .175 & .914 & -.36 & .50 \\
\hline & & Green tea & .032 & .175 & .982 & -.40 & .47 \\
\hline & \multirow[t]{2}{*}{ White tea } & Chlorhexidine & -.071 & .175 & .914 & -.50 & .36 \\
\hline & & Green tea & -.039 & .175 & .973 & -.47 & .39 \\
\hline & \multirow[t]{2}{*}{ Green tea } & Chlorhexidine & -.032 & .175 & .982 & -.47 & .40 \\
\hline & & White tea & .039 & .175 & .973 & -.39 & .47 \\
\hline \multirow[t]{6}{*}{ PI POST } & \multirow[t]{2}{*}{ Chlorhexidine } & White tea & -.14300 & .12663 & .505 & -.4570 & .1710 \\
\hline & & Green tea & $-.33300^{*}$ & .12663 & .036 & -.6470 & -.0190 \\
\hline & \multirow[t]{2}{*}{ White tea } & Chlorhexidine & .14300 & .12663 & .505 & -.1710 & .4570 \\
\hline & & Green tea & -.19000 & .12663 & .307 & -.5040 & .1240 \\
\hline & \multirow[t]{2}{*}{ Green tea } & Chlorhexidine & $.33300^{*}$ & .12663 & .036 & .0190 & .6470 \\
\hline & & White tea & .19000 & .12663 & .307 & -.1240 & .5040 \\
\hline \multirow[t]{2}{*}{ GI PRE } & \multirow[t]{2}{*}{ Chlorhexidine } & White tea & $.24100^{*}$ & .09258 & .038 & .0115 & .4705 \\
\hline & & Green tea & .14800 & .09258 & .264 & -.0815 & .3775 \\
\hline
\end{tabular}




\begin{tabular}{|c|c|c|c|c|c|c|c|}
\hline & \multirow{2}{*}{ White tea } & Chlorhexidine & $-.24100^{*}$ & .09258 & .038 & -.4705 & -.0115 \\
\hline & & Green tea & -.09300 & .09258 & .580 & -.3225 & .1365 \\
\hline & \multirow[t]{2}{*}{ Green tea } & Chlorhexidine & -.14800 & .09258 & .264 & -.3775 & .0815 \\
\hline & & White tea & .09300 & .09258 & .580 & -.1365 & .3225 \\
\hline \multirow[t]{6}{*}{ GI POST } & \multirow[t]{2}{*}{ Chlorhexidine } & White tea & $-.19600^{*}$ & .06401 & .013 & -.3547 & -.0373 \\
\hline & & Green tea & -.09600 & .06401 & .307 & -.2547 & .0627 \\
\hline & \multirow[t]{2}{*}{ White tea } & Chlorhexidine & $.19600^{*}$ & .06401 & .013 & .0373 & .3547 \\
\hline & & Green tea & .10000 & .06401 & .279 & -.0587 & 2587 \\
\hline & \multirow[t]{2}{*}{ Green tea } & Chlorhexidine & .09600 & .06401 & .307 & -.0627 & .2547 \\
\hline & & White tea & -.10000 & .06401 & .279 & -.2587 & .0587 \\
\hline \multirow[t]{6}{*}{ CFU PRE } & \multirow[t]{2}{*}{ Chlorhexidine } & White tea & 2.700 & 6.923 & .920 & -14.46 & 19.86 \\
\hline & & Green tea & 4.900 & 6.923 & .761 & -12.26 & 22.06 \\
\hline & \multirow[t]{2}{*}{ White tea } & Chlorhexidine & -2.700 & 6.923 & .920 & -19.86 & 14.46 \\
\hline & & Green tea & 2.200 & 6.923 & .946 & -14.96 & 19.36 \\
\hline & \multirow[t]{2}{*}{ Green tea } & Chlorhexidine & -4.900 & 6.923 & .761 & -22.06 & 12.26 \\
\hline & & White tea & -2.200 & 6.923 & .946 & -19.36 & 14.96 \\
\hline \multirow[t]{6}{*}{ CFU POST } & \multirow[t]{2}{*}{ Chlorhexidine } & White tea & $-21.200^{*}$ & 4.835 & .000 & -33.19 & -9.21 \\
\hline & & Green tea & -3.000 & 4.835 & .810 & -14.99 & 8.99 \\
\hline & \multirow[t]{2}{*}{ White tea } & Chlorhexidine & $21.200^{*}$ & 4.835 & .000 & 9.21 & 33.19 \\
\hline & & Green tea & $18.200^{*}$ & 4.835 & .002 & 6.21 & 30.19 \\
\hline & \multirow[t]{2}{*}{ Green tea } & Chlorhexidine & 3.000 & 4.835 & .810 & -8.99 & 14.99 \\
\hline & & White tea & $-18.200^{*}$ & 4.835 & .002 & -30.19 & -6.21 \\
\hline
\end{tabular}

*. The mean difference is significant at the 0.05 level.

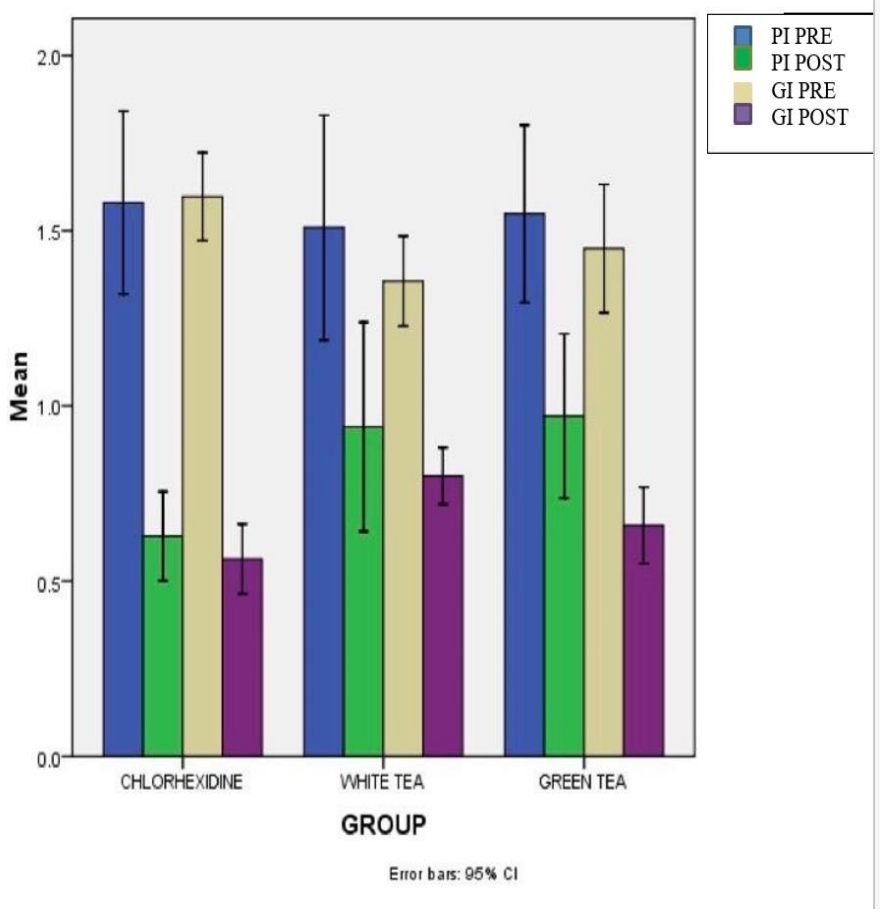

Fig. 1: Comparison of various clinical parameters at various time intervals 


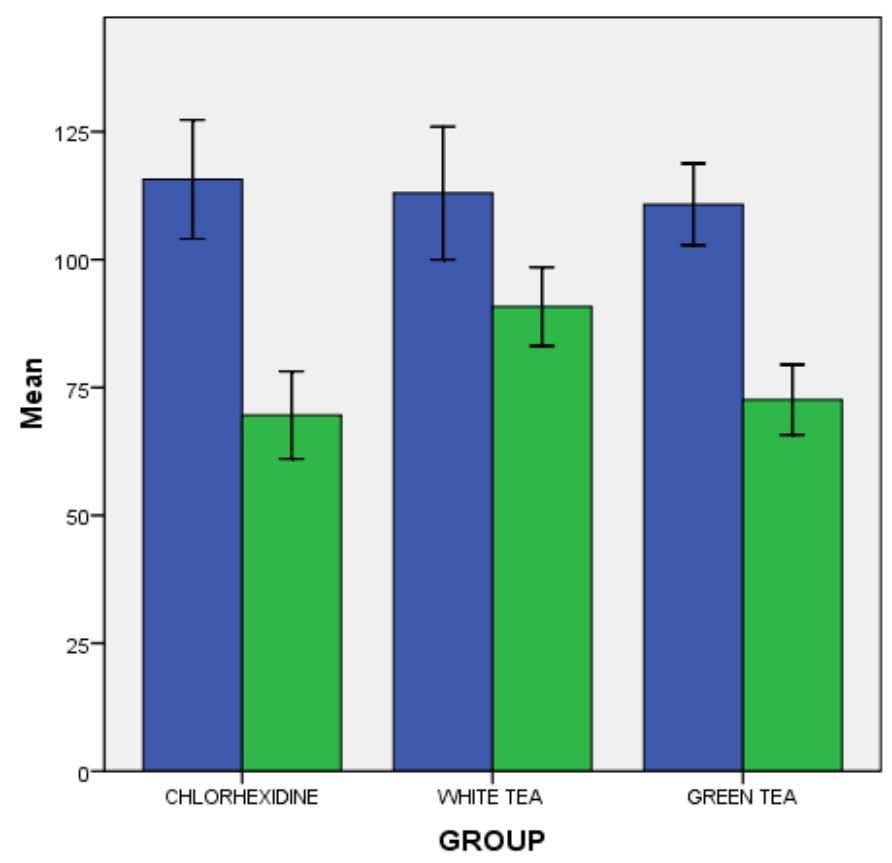

$\square$ PIPRE

$\square$ PIPOST

Error bars: $95 \% \mathrm{cl}$

Fig. 2: Comparison of CFU in 3 groups

\section{Conflict of Interest: None.}

\section{Reference}

1. de Oliveira SM, Torres TC, Pereira SL, Mota OM, Carlos MX. Effect of adentifrice containing Aloe vera on plaque and gingivitis control. A double-blind clinical study in humans. J Appl Oral Sci 2008;16(4):293-96.

2. Ketabi M, Tazhibi M, Mohebrasool S. The plevelance and risk factors of gingivitis among children referred to Islamic Azad University (Khorasgan Branch) Dental School, in Iran. Dent Res J 2006;3(1):1-3

3. Hirasawa K, Takada S, Otake. Inhibition of acid production in dental plaque bacteria by green tea catechins. Caries Res 2006;40(3):265-70

4. Soukoulis S, Hirsch R The effect of tea tree oil containing gel on plaque and chronic gingivitis. Aust Dent $J$ 2004;49(2):78-83

5. Lorenzo JM, Munekata SEP. Phenolic compounds of green tea: Health benefits and technological application in food. APJTB 2016;6(8):709-19

6. Hirasawa M, Tahada K, Makimura M, Otake S.

Improvement of periodontal status by green tea catechin using a local delivery system: a clinical pilot study. $J$ Periodontal Res 2002;37(6):433-38.

7. Zhen MC, Huang XH, Wang Q, Sun K, Liu YJ, Li W, et al. Green tea polyphenol epigallocatechin-3-gallate suppresses rat hepatic stellate cell invasion by inhibition of MMP-2 expression and its activation. Acta Pharmacol $\operatorname{Sin} 2006 ; 27(12): 1600-7$

How to cite the article: Nagar A, Tyagi A, Gupta SJ, Banga A, Sharma N, Gupta A. Comparatie evaluation of the anti-plaque efficacy of green tea extract mouthrinse and white tea extract mouthrinse with chlorhexidine gluconate mouthrinse-A clinical and microbiological study. J Dent Specialities 2018;6(2):109-114. 